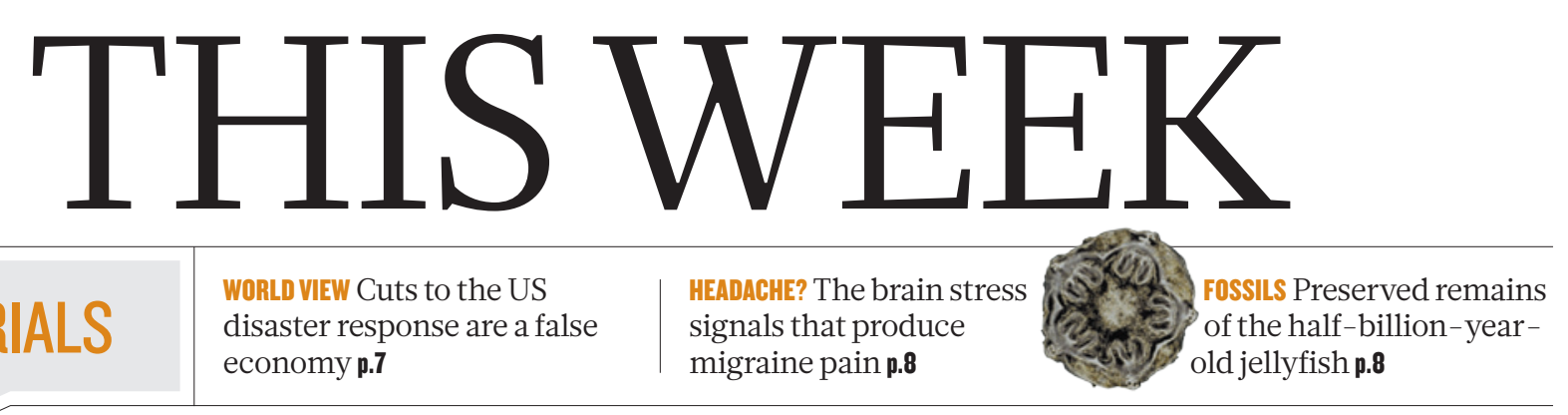

EDITORIALS disaster response are a false economy $\mathbf{p . 7}$

\title{
Science for all
}

\section{Many women are deterred from pursuing a career in science at the highest levels. Much more must be done to address the reasons behind this potential waste of human talent.}

$\mathrm{W}$ hether female scientists will want to celebrate International Women's Day on 8 March may depend on how far they look back in time. Things have changed, and if you talk in terms of decades, there are considerable victories to cheer about. But despite those victories, progress now seems to have stalled.

That is clear from the package of articles in this week's Nature (see page 21) that exposes the dismaying extent to which sexism still exists in science. In the United States and Europe, around half of those who gain doctoral degrees in science and engineering are female - but barely one-fifth of full professors are women. Women are not invited in significant numbers to sit on the scientific advisory boards of start-up companies. A scientific conference at which half of the keynote speakers are women stands out simply because of that.

Why has progress stalled? Childcare is one major factor that blocks the career of many women. But that is a practical issue, theoretically easy to fix given political will. Even the most enlightened childcare policies will not fix a second, more insidious major problem: overt or unconscious gender bias. It can be detected even in female scientists, and even, according to neurobiologist Jennifer Raymond (see page 33), in those who actively promote women within science.

\section{POLITICS}

The fate of women in science can be influenced for good and bad by political systems. In communist China, women and men had a fairly equal presence in science until recently, when its tottering attempts to open up to the capitalist world led to a disproportionate recruitment of young men returning from research training abroad. This sets the stage for gender imbalance in the future. At the other end of the political spectrum, Portugal's twentieth-century dictatorship similarly managed to secure a healthy balance of female professors. That may have been for the wrong reasons, such as that those jobs were of low salary and prestige, or because a bellicose foreign policy sent male graduates to fight in colonial wars. Most of those men chose to stay abroad, leaving the academic field open for women. The role models were therefore in place when Portugal became a democracy in 1974 and began to invest in research in the 1990s. A healthy gender balance continues there.

The worrying gender bias in mature democracies won't be resolved by the flick of a master switch. As in most professions, it is locked in place by male dominance at all the levels of decision-making that affect academic careers - from journal editorial boards, to grant-reviewing boards, to academic selection committees. Women are barely visible at these levels, fixing the subconscious idea that science belongs to men. There are many ways to chip away at this invisibility and they should all be tried, with the results published so that others can learn from them.

One serious proposal is the imposition of quotas. In certain contexts, such as academic promotions, this would be a good way to ensure that young female scientists have female role models. Some argue that setting a quota for women in leading academic positions such as professorships will result in mediocre female candidates being promoted. But there is a gap in reasoning here. Women and men are equally talented, so if men occupy a large majority of high-level posts, there must be an awful lot of mediocrity among their number. Is mediocrity more acceptable in men? Quotas on decision-making committees, however, do come with the inbuilt problem of overburdening the few women who already hold top positions. The solution here would be to keep the quota realistically low for now.

\section{PROFILE RAISING}

Individuals - from Nobel prizewinners to lowly postdocs - have a part to play. Some laureates have contributed with foundations. The Rita Levi-Montalcini Foundation supports young women in Africa who wish to become scientists. The Christiane NüssleinVolhard Foundation supports young female scientists with children. And other scientists engage in various consciousness-raising activities.

At the institutional level, several European research agencies and institutions have special funding programmes for women, allowing them to establish their own labs. Last November, Nature made a public challenge to itself by reporting that only $14 \%$ of its reviewers and $19 \%$ of its invited Comment and World View authors were female (see Nature 491, 495; 2012). We vowed to improve, and have asked our editors to try harder to engage with women. In time, we will make our progress public.

One useful tool is the online platform AcademiaNet (http://academianet.info), created by the Stuttgart-based Robert Bosch Foundation in Germany in cooperation with Spektrum der Wissenschaft, the German edition of Scientific American (which is owned by the Nature Publishing Group). AcademiaNet gives a web presence to high-achieving female scientists, making them visible to conferenceprogramme committees seeking female speakers, journalists seeking experts to quote, head-hunters seeking board members and the like. The network will become even more important as work to address gender imbalance accelerates. With successful women being both fewer and less likely to push themselves forward than their male counterparts, they can be hard to find for even the most enthusiastic gender-balancer.

AcademiaNet was opened in 2010 by German chancellor Angela Merkel, a former physicist, who stressed how important it is to preserve half of a country's scientific potential. She recalled her own difficulties training with men who would rush impulsively to try to solve practicalclass problems. Her style was to think and then try out, by which time the equipment was occupied or broken. Might an option for separate training in some areas be useful for women, she pondered? Merkel knows a thing or two about being a successful woman, so let's add her idea to that list of things to try. It's a long list. It's time to get started. What are you waiting for? 